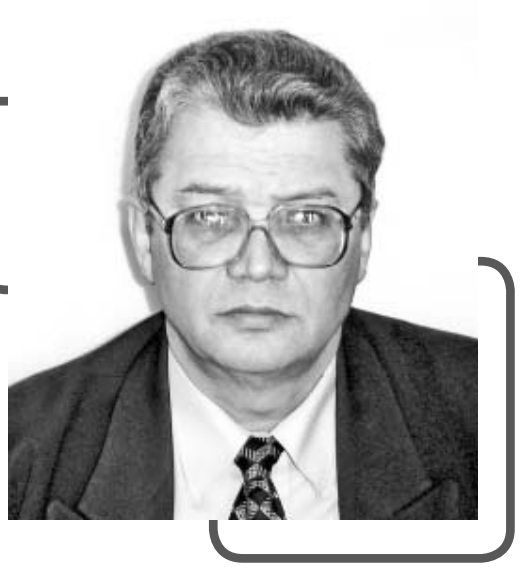

Триер, зерносмесь, очистка, подача, засорённость, режим работы, настройка, интенсивность процесса

Sifting cylinder, grain mixture, cleaning, feed, weediness, operating mode, setting, process intensity

\section{ИНТЕНСИВНОСТЬ ВЫДЕЛЕНИЯ ЗЕРНОВОК ОСНОВНОЙ КУЛЬТУРЫ ИЗ ЗЕРНОСМЕСЕЙ С ДЛИННЫМИ ПРИМЕСЯМИ}

\author{
Н.П. Тишанинов (фото)
}

д.т.н., профессор, главный научный сотрудник лаборатории управления качеством технологических процессов в сельском хозяйстве

\section{А.В. Анашкин}

к.т.н., ведущий научный сотрудник лаборатории управления качеством технологических процессов в сельском хозяйстве ФГБНУ «Всероссийский научно-исследовательский институт использования техники и нефтепродуктов в сельском хозяйстве», г. Тамбов

Динамика выделения зерновок основной культуры из зерносмеси по длине овсюжного цилиндра изучена недостаточно. Из-за этого известные авторы [1-3] и многие другие предлагают рассчитывать производительность триеров по удельной нагрузке на единицу площади ячеистой поверхности. При этом утрачивается связь расходных характеристик с режимами работы и настроечными параметрами, что противоречит базовым положениям теории триеров.

Кроме того, для управления технологическим процессом необходимо знать взаимосвязь величины загрузки триера с величиной используемой ячеистой поверхности в осевом направлении. По этой взаимосвязи необходимо производить настройку триера так, чтобы ячеистая поверхность по всей длине была включена в процесс выделения зерновок основной культуры. В противном случае свободная ячеистая поверхность захватывает связные примесные частицы и подаёт их в выводной лоток, ухудшая качество работ.

\section{Материалы и методы}

Исследования проводили на пшенице с насыпной плотностью $805 \mathrm{kг} / \mathrm{M}^{3}$ и массой 1000 зерновок (52 г). Примесным компонентом был овсюг со средней длиной частиц 12,54 мм, массой 1000 частиц 25,2 г. В работе использовались специальные стенды [4-5], разработанные в ФГБНУ ВНИИТиН, обеспечивающие получение закономерностей процессов разделения зерносмесей в широком диапазоне их производительности. В процессе исследований рассматривались закономерности взаимосвязей интенсивности выделения зерновок основной культуры по интервальным участкам длины овсюжного цилиндра с величинами: исходной концентрации примесного компонента в зерносмеси; угла подъёма верхней кромки передней стенки выводного лотка; радиального зазора $\left(3_{p}\right)$ между верхней 
кромкой и внутренней поверхностью ячеистого цилиндра и скоростью его вращения (табл. 1).

\section{Результаты исследований}

На рисунке 1 показана взаимосвязь интенсивности выделения зерновок основной культуры из зерносмеси в массовых долях с величиной угла подъёма верхней кромки передней стенки выводного лотка. Условия эксперимента были следующими: скорость вращения ячеистого цилиндра составляла 35 об/мин; исходная засорённость зерносмеси - 1\%; радиальный зазор между верхней кромкой передней стенки выводного лотка и внутренней поверхностью ячеистого цилиндра составлял 20 мм.
Из рисунка 1 видно, что интенсивность выведения зерновок основной культуры из зерносмесей падает с увеличением угла подъёма верхней кромки передней стенки выводного лотка. Изменение представленных на рисунке 1 зависимостей объясняется следующим. На протяжении первых интервалов времени замеров происходит увеличение интенсивности, так как снижается эффект динамического «выедания» зерновок из ячей при максимальной толщине сегмента (при максимальном числе циркулирующих слоёв зерна в сегменте). Далее наблюдается узкая зона максимальной интенсивности выведения, после чего резко снижается число циркулирующих слоёв в сегменте, снижается эффект инерционного удер-

Таблица 1 - Состав исследуемых факторов, уровни и интервалы их варьирования

\begin{tabular}{|l|c|c|c|c|}
\hline \multicolumn{1}{|c|}{ Наименование факторов } & Обозначение & Ед. изм. & Диапазон & Интервал \\
\hline Скорость вращения цилиндра & $n$ & об/мин & $30 \ldots 40$ & 10 \\
\hline Исходная засорённость зерносмеси & $3_{u}$ & $\%$ & $1 \ldots 3$ & 1 \\
\hline $\begin{array}{l}\text { Угол подъёма верхней кромки передней стенки } \\
\text { выводного лотка относительно горизонта }\end{array}$ & $\gamma_{n}$ & град. & $20 \ldots 40$ & 10 \\
\hline Радиальный зазор & $3_{p}$ & мм & $10 \ldots 20$ & 5 \\
\hline
\end{tabular}

жания зерновок в ячеях, и степень заполнения ячей становится меньше единицы. На заключительном этапе выделения зерновок основной культуры число циркулирующих слоёв становится меньше единицы, и вероятность захвата зерновок ячеями становится минимальной - зерновки при динамическом взаимодействии с ячеистой поверхностью поднимаются над ней, их захват ячеями становится маловероятным.

Из сказанного выше нами принят 95\%-ный уровень выделения зерновок основной культуры для сопоставительной оценки продолжительности процесса в зависимости от величины $\gamma_{n}$. Этот уровень выделения зерновок основной культуры

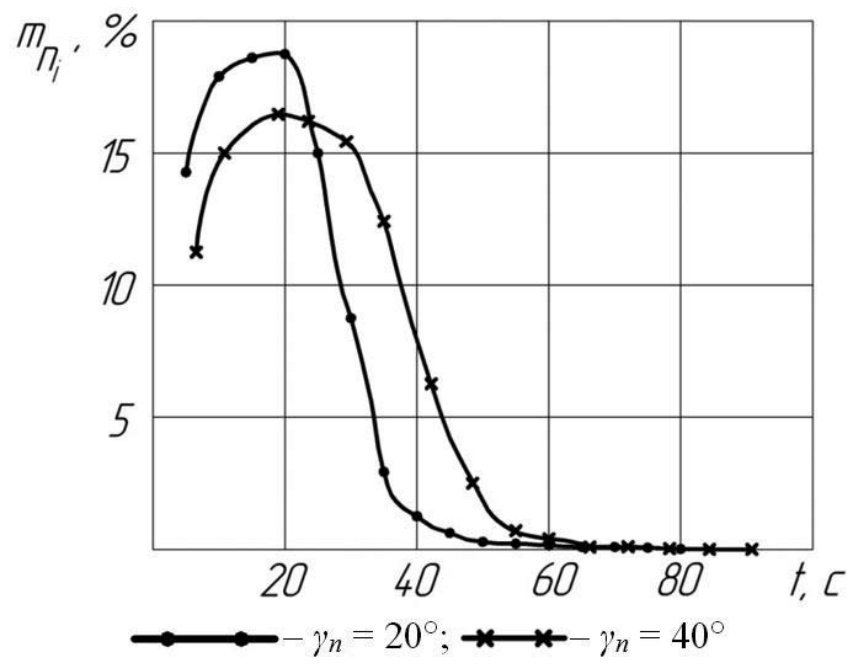

Рисунок 1 - Интенсивность выделения зерновок основной культуры из зерносмеси в зависимости от $\gamma_{n}$ при: $\mathrm{n}=35$ об/мин; $3_{u}=1 \% ; 3_{p}=20$ мм 
(С95) обеспечивается за 32 с при $\gamma_{n}=20^{\circ}$; при $\gamma_{n}=$ $30^{\circ}-39,3$ с; при $\gamma_{n}=40^{\circ}-44,8$ c.

Максимальная интенсивность выделения зерновок основной культуры из зерносмеси при наименьшей величине угла $\gamma_{n}$ объясняется тем, что выводным лотком захватывается большая часть факела частиц, выброшенных ячеями. Увеличение $\gamma_{n}$ с $20^{\circ}$ до $30^{\circ}$ приводит к росту продолжительности выделения зерновок основной культуры на 23\%, а последующее увеличение угла $\gamma_{n}$ до $40^{\circ}$ увеличивает продолжительность 95\%-го уровня выделения зерновок основной культуры до 44,8 c.

Увеличение исходной засорённости зерносмесей с $1 \%$ до $2 \%$ увеличивает продолжительность 95\%-ной степени выделения зерновок основной культуры до 46 с, что эквивалентно снижению интенсивности выделения на 2,7\%. Дальнейшее увеличение исходной засорённости зерносмеси с 2\% до 3\% привело к снижению максимальной интенсивности выведения зерновок основной культуры лишь в 4-м интервале измерений - на $2,5 \%$.

Представленные выше результаты получены при эквивалентной загрузке овсюжного цилиндра стандартного триерного блока (ЗАВ10.90.000A) $W=1,36$ т/ч. При этом 95\%-ный уровень выделения зерновок основной культуры обеспечивается частичной загрузкой длины овсюжного цилиндра в зависимости от величины $\gamma_{n}$ : $\gamma_{n}=20^{\circ} \rightarrow 37 \% ; \gamma_{n}=30^{\circ} \rightarrow 45,4 \% ; \gamma_{n}=40^{\circ} \rightarrow 51,7 \%$.

С увеличением величины эквивалентной подачи зерносмеси в овсюжный цилиндр до $W=$ 2,9 т/ч при условиях опыта ( $n=35$ об/мин; $\gamma_{n}=20^{\circ}$; $3_{u}=1 \% ; 3_{p}=20$ мм) получено увеличение интенсивности выделения зерновок основной культуры относительно результатов, полученных в идентичных условиях при $W=1,36$ т/ч. Прирост по 10-секундным интервалам замеров составил: 1-й - 14\%; 2-й - 10,7\%; 3-й - 66\%. В последующих интервалах прирост был ещё большим из-за увеличения общей продолжительности $\left(t_{95}\right)$ выделения зерновок основной культуры: $\gamma_{n}=20^{\circ} \rightarrow t_{95}$ $=42 \mathrm{c} ; \gamma_{n}=30^{\circ} \rightarrow t_{95}=49 \mathrm{c} ; \gamma_{n}=40^{\circ} \rightarrow t_{95}=61 \mathrm{c}$. При этом загрузка овсюжного цилиндра по длине составляет: $\gamma_{n}=20^{\circ} \rightarrow 65,7 \% ; \gamma_{n}=30^{\circ} \rightarrow 76,6 \%$; $\gamma_{n}=40^{\circ} \rightarrow 95,4 \%$.
Увеличение 3 до $2 \%$ практически не влияет на интенсивность процесса выделения при $W=$ 2,9 т/4 во всём диапазоне изменения $\gamma_{n^{\prime}}$ так как число циркулирующих слоёв в сегменте увеличилось более чем в 2 раза в сравнении с вариантом, когда $W=1,36$ т/ч. Поэтому условия захвата зерновок основной культуры ячеями изменились несущественно. Не изменилась интенсивность процесса выделения зерновок основной культуры и при $3_{u}=3 \%$ - те же значения $t_{95}$ при $\gamma_{n}=20^{\circ}$; $30^{\circ}$ и $40^{\circ}$.

Увеличение скорости вращения овсюжного цилиндра с 35 об/мин до $n=40$ об/мин (на 14,3\%) привело к увеличению интенсивности процесса выделения зерновок на соответствующих интервалах времени измерений в 1,5 раза и сокращению $t_{95}$ в 1,5 раза. Непропорциональный рост показателей интенсивности процесса относительно приращения скоростного режима объясняется эффектом инерционного удержания контактирующего с ячеистой поверхностью слоя зерновок, который частично попадает в факел выброса частиц ячеями.

Инерционный захват зерновок из контактирующего слоя увеличивает угол факела выброса частиц ячеями. Это подтверждается снижением интенсивности процесса выделения зерновок и ростом $t_{95}$ при уменьшении радиального зазора $\left(3_{p}\right)$. При $n=40$ об/мин, $\gamma_{n}=40^{\circ} ; 3_{u}=3 \%$ взаимосвязь указанных величин следующая: $3_{p}=20 \mathrm{MM} \rightarrow$ $t_{95}=40 \mathrm{c} ; 3_{p}=15 \mathrm{MM} \rightarrow t_{95}=43 \mathrm{c} ; 3_{p}=10 \mathrm{MM} \rightarrow t_{95}=$ $44,7 \mathrm{c}$.

\section{Выводы}

Эффективное управление работой триера с целью максимального использования рабочей длины ячеистого цилиндра на различных подачах в него зерносмесей с длинными примесями обеспечивается изменением углового положения выводного лотка и скоростного режима работы достигается кратное изменение интенсивности процесса. Изменение радиального зазора между выводным лотком и внутренней поверхностью ячеистого цилиндра с 20 мм до 10 мм снижает интенсивность процесса лишь на 11,7\%. Дальнейшее уменьшение радиального зазора невозможно из-за непрерывных технологических отказов.

\section{Лumepamypa}

1. Листопад, Г.Е. Сельскохозяйственные и мелиоративные машины [Текст] / Г.Е. Листопад. - М.: Агропромиздат, 1986. - 687 с.

2. Лурье, А.Б. Расчет и конструирование сельскохозяйственных машин [Текст] / А.Б. Лурье. - Л.: Машиностроение, 1997. - 526 с. 
3. Соколов, А.Я. Технологическое оборудование предприятий по хранению и переработке зерна [Текст] / А.Я. Соколов. - Изд. 4-е доп. и перераб. - М.: Колос, 1975. - 495 с.

4. Тишанинов, Н.П. Теоретические предпосылки поиска резервов управления процессами триерной очистки зерносмесей [Текст] / Н.П. Тишанинов, А.В. Анашкин // Наука в центральной России. - 2014. - № 6 (12). - C. 28-38.

5. Пат. 2616201 Российская Федерация, МПК ВО7В 13/02. Стенд для испытаний ячеистых поверхностей [Текст] / Тишанинов Н.П., Анашкин А.В., заявитель и патентообладатель ФГБНУ ВНИИТиН. - № 2016108182; заявл. 09.03.16; опубл. 13.04.17, Бюл. № 11.

\section{References}

1. Listopad, G.E. Sel'skohozjajstvennye i meliorativnye mashiny [Tekst] / G.E. Listopad. - M.: Agropromizdat, 1986. $-687 \mathrm{~s}$.

2. Lur'e, A.B. Raschet i konstruirovanie sel'skohozjajstvennyh mashin [Tekst] / A.B. Lur'e. - L.: Mashinostroenie, 1997. $-526 \mathrm{~s}$.

3. Sokolov, A.Ya. Tehnologicheskoe oborudovanie predprijatij po hraneniju i pererabotke zerna [Tekst] / A.Ya. Sokolov. - Izd. 4-e dop. i pererab. - M.: Kolos, 1975. - 495 s.

4. Tishaninov, N.P. Teoreticheskie predposylki poiska rezervov upravlenija processami triernoj ochistki zernosmesej [Tekst] / N.P. Tishaninov, A.V. Anashkin // Nauka v central'noj Rossii. - 2014. - № 6 (12). - S. $28-38$.

5. Pat. 2616201 Rossijskaja Federacija, MPK VO7V 13/02. Stend dlja ispytanij jacheistyh poverhnostej [Tekst] / Tishaninov N.P., Anashkin A.V., zajavitel' i patentoobladatel' FGBNU VNIITiN. - № 2016108182; zajavl. 09.03.16; opubl. 13.04.17, Bjul. № 11.

\section{ОБЫЯВЛЕНИЕ}

В издательстве ФГБОУ ВО Ярославская ГСХА в 2019 году вышло учебное пособие, получившее гриф Федерального УМО по сельскому, лесному и рыбному хозяйству

для обучающихся по направлению подготовки 35.03.06 «Агроинженерия»

(профиль «Электрооборудование и электротехнологии в АПК»)

«ЛИНЕЙНЫЕ ЭЛЕКТРИЧЕСКИЕ ЦЕПИ"

АвторЫ: В.В. МОРОЗОВ, П.С. ОРЛОВ, В.В. ШМИГЕЛЬ

УЧЕБНОЕ ПОСОБИЕ СОДЕРЖИТ СВЕДЕНИЯ, НЕОБХОДИМЫЕ ДЛЯ ФОРМИРОВАНИЯ ПРОФЕССИОНАЛЬНЫХ КОМПЕТЕНЦИЙ

ПРИ ПОДГОТОВКЕ БАКАЛАВРОВ ПО НАПРАВЛЕНИЮ «АГРОИНЖЕНЕРИЯ»,

И РЕКОМЕНДУЕТСЯ НАУЧНО-МЕТОДИЧЕСКИМ СОВЕТОМ

ПО ТЕХНОЛОГИЯМ, СРЕДСТВАМ МЕХАНИЗАЦИИ И ЭНЕРГЕТИЧЕСКОМУ

ОБОРУДОВАНИЮ В СЕЛЬСКОМ ХОЗЯЙСТВЕ ФЕДЕРАЛЬНОГО УМО

ПО СЕЛЬСКОМУ, ЛЕСНОМУ И РЫБНОМУ ХОЗЯЙСТВУ

ДЛЯ ИСПОЛЬЗОВАНИЯ В УЧЕБНОМ ПРОЦЕССЕ.

В учебном пособии представлены курс лекций и практические работы по разделу «Линейные электрические цепи» дисциплины «Теоретические основы электротехники» с контрольными вопросами и задачами для самопроверки обучающихся.

УДК 621.317; ББК 31.21; ISBN 978-5-98914-201-9; 334 СТР.

ПО ВОПРОСАМ ПРИОБРЕТЕНИЯ ОБРАЩАТЬСЯ ПО АДРЕСУ: 150042, г. Ярославль, Тутаевское шоссе, 58, ФГБОУ ВО Ярославская ГСХА e-mail: e.bogoslovskaya@yarcx.ru 